A tale of how it turned out right

\section{The Great Transition}

\author{
Creating a new kind of economy is crucial if we want to tackle \\ climate change and avoid the mounting social problems \\ associated with the rise of economic inequality. The study \\ 'The Great Transition' provides the first comprehensive \\ blueprint for building an economy based on stability, \\ sustainability and equality. \\ By Eva Neitzert and Stephen Spratt
}

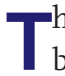
he frantic attempts of political and business leaders to restore business as usual appear to have borne fruit. At the start of 2010, just 18 months after the collapse of Lehman Brothers ushered in the most significant financial and economic crisis of the post-war period, most developed economies have returned to growth.

Yet there seems little reason to celebrate. Aftershocks of the crisis continue to hit world markets suggesting that, despite the return to growth, we are not on a sustainable economic path. And on other fronts there are problems too.

The Copenhagen Conference underscored the magnitude and urgency of the climate and environmental crises. Gaping

Figure 1: Business as usual scenario depicting GDP, cumulative costs associated with climate change and annual cost of social ills associated with inequality to 2050 .

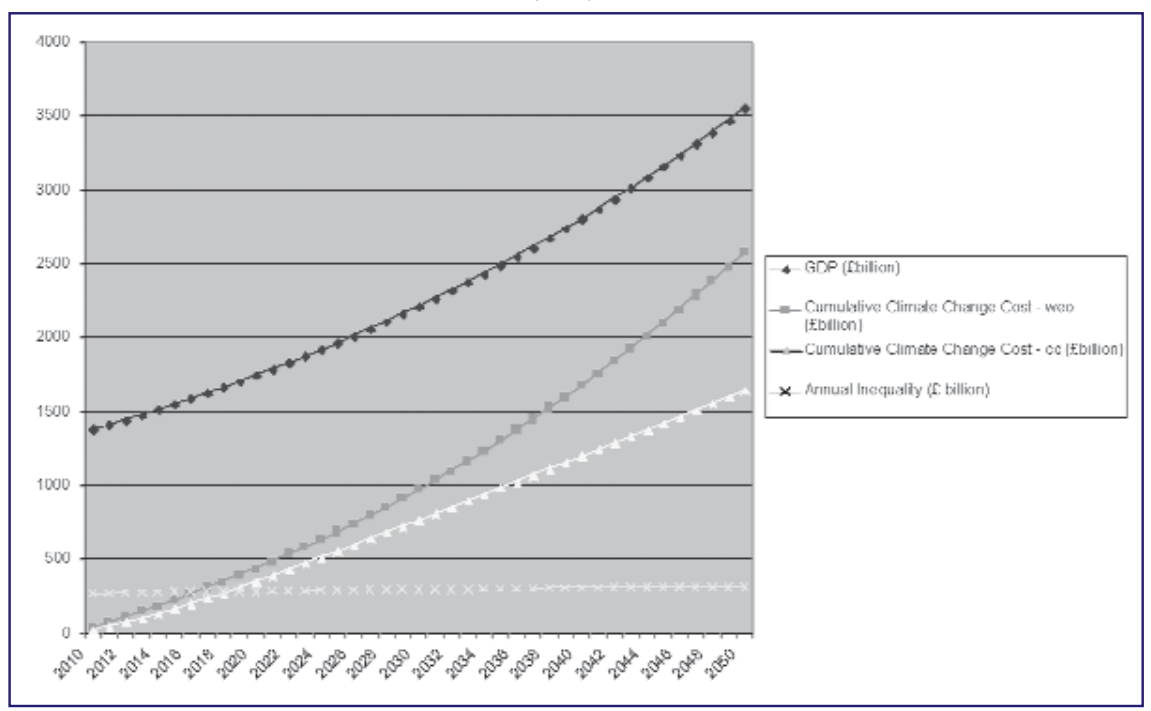

Source: Spratt et al. 2009
Polanyi in the 1940s, to acknowledge that the scale of the change we need is at least the equal of the changes he described (Polanyi 1944).

This article discusses some of the key findings of the Great Transition project. It examines first the limits to business as usual, before turning to how the reorganisation of economic and social affairs can create value even in the context of declining Gross Domestic Product (GDP). The focus of the research was the United Kingdom, but much of it applies equally to other developed economies.

\section{The limits to business as usual}

It is hard to see how it could be done but, for arguments sake, what might the United Kingdom (UK) look like in 2050 if politicians manage to maintain, against all odds, the UK on an even growth path.

Figure 1 projects what could happen to GDP and costs associated with climate change and inequality in the United Kingdom under a 'business as usual' scenario. The assumptions underpinning this scenario are deliberately optimistic. It was not our intention construct a frightening scenario, but to give a clear-eyed picture of a possible future. GDP has been plotted as following a steady growth path and we assume that inequality remains at 2006 levels. For climate change we have modelled two separate cases. One, the 'CC' scenario, takes politicians at their word and plots what could happen if the UK Climate Change Act targets of an 80 per cent reduction by 2050 and maximum concentration of $550 \mathrm{ppm}$ are reached. Given the rate at which emissions are increasing and the lack of concerted policy measures being put in place to try to reverse this, we felt it necessary to also project a more realistic scenario and have used the projections of the World Energy Outlook (WEO).

Even in the optimistic scenario where Climate Change Act targets are met, the UK is facing high costs. While GDP is certainly higher, the cumulative cost of climate change and the cost of abatement have reached $£ 1$. 6 trillion. This gets much 
worse when we consider the more realistic WEO scenario. Here the cumulative costs by 2050 are expected to reach $£ 2.5$ trillion.

Similarly, by failing to address the high levels of inequality in the UK the cost of preventable associated social ills, such as poor health outcomes and high levels of crime and family breakdown, remains at the high levels seen today. The graph plots annual costs in figure 1 because the cumulative total would dwarf the other amounts and distort the graph. The cumulative total over this period for the cost of social ills associated with inequality exceeds $£ 4.5$ trillion.

\section{From crisis come opportunity}

The Great Transition project started from a simple premise that there must be a better way and from a simple question: what if we begin not from growth as our goal, but with a goal of maximising real social value for all within the confines of what is possible, given the planet's carrying capacity and the UK's equitable share within these limits?

The environmental limits meant that there would be constraints on GDP. In our models, GDP as it is calculated now will fall, maybe by as much as a third. This begs the question: can you do more with less? Can you maximise value for individuals, communities and the environment at the same time that GDP falls?

People rightly associate falling GDP with rising unemployment, poverty and general misery. The way our economy has been structured is such that this has indeed been the case. A central goal of the Great Transition is to manage this change in such a way that we are better off not worse off. We think that this can be done. GDP is a very poor measure of progress: the revenues skimmed off the financial system by traders in the City of London as the pyramid of 'toxic' deriva- tives was being built added to GDP; cleaning up the effects of pollution increases GDP; paying the costs of high rates of crime increases GDP. None of these things can be said to build lasting social or environmental value. Rather, they are highly destructive of it.

The Great Transition report sketches out a seven step process for maximising value even while gross output falls. These steps require us to think much more intelligently about how we organise our economy and society than we have done till now. Realising the Great Transition that is sketched out in the report would see value rise steadily across three dimensions: for individuals, through a more equal distribution of incomes and assets; for society, by reducing the costs associated with inequality; for future generations, by protecting the natural environment and so reducing climate change-related costs.

We do not have scope to set out in detail the seven steps of the Great Transition in this article, but want to share the findings of the scenario modelling which provides an indication of the value that can be created by undertaking such a reorganisation.

First, though, a health warning. This modelling requires financial proxies to be attached to social and environmental outcomes. This is an imperfect method of valuation, as all assessments of value are subjective and therefore fraught with difficulty. This does not make it a futile exer-

cise; it is an illustrative example to demonstrate how the pursuit of well-being and wider social and environmental value could be achieved without growing GDP. In the absence of anything better, monetary valuations are used as an approximation - a 'vaguely right, rather than precisely wrong' approach - not to place a fixed price on something but using money simply as a common unit of account in our calculations.

Figure 2 shows how value progressively increases across all three domains from 2010 to 2050 if the Great Transition is pursued. So how is this value created for each dimension?

\section{Individual value}

Even from an orthodox, neoclassical economics perspective, unequal societies are highly inefficient in terms of utility maximisation. Utility is a central concept in economics but economists have paid little attention to the total utility loss that occurs when income is distributed unevenly.

An important part of the Great Transition is a progressive redistribution of incomes to maximise utility. Income is transferred from high-income to low-income households over a period of 20 years in 5 waves. This is done in such a way that post-redistribution, no household has an income of less than $£ 13,900$ - a figure that a recent study by the Joseph Rowntree Foundation identified as the basic minimum for the UK (Bradshaw et al.

Figure 2: Cumulative value creation in three dimensions: individual, social and environmental.

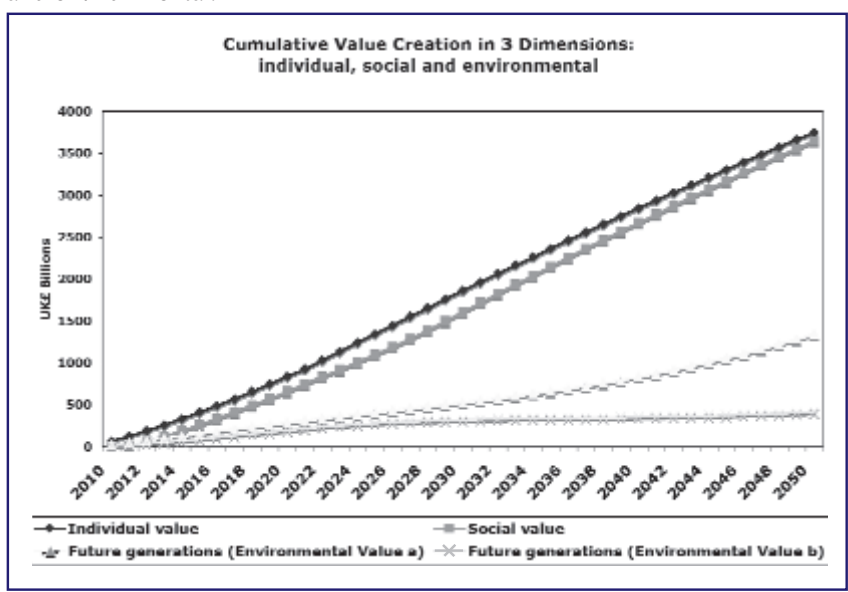

Source: Spratt et al. 2009
2008). The resulting income distribution is far from unrealistic. It is actually the same as Denmark today.

Our model calculates the additional value that is created by moving money from households where little utility is derived to households that will get greater utility. The percentage change in moving from pre- to post-redistribution is 8.49 per cent. This is the equivalent to a cumulative gain of $£ 3,752$ bil- 
lion from 2010 to 2050, as shown by the blue line in Figure 2.

\section{Social value}

Unequal societies are not just bad for people at the bottom end of the income distribution - they are bad for everyone in society. Unequal societies have worse outcomes across nearly every social domain: health, life expectancy, education, and crime, to name but a few.

These outcomes are undesirable in and of themselves - few would choose to live in a society with very bad outcomes in these areas if they could do something about it. But they are also a significant and preventable expense to the public purse or to the economy as a whole. Given the established link between levels of inequality and the incidence of these outcomes, we believe that we can build real social value by reducing inequality and so reducing the prevalence of associated social ills (Wilkinson/Pickett 2009).

By building a more equal society through the Great Redistribution, the incidence of these poor outcomes is reduced. Our model places conservative estimates on the social value of greater equality from reduced social problems in areas such as health, education and crime. This value includes not just the savings to society from reduced dependence on public services to deal with the impacts of these problems but also the benefits to people and communities from not having to live with the consequences of high crime, low attainment, family breakdown and ill health.

\section{Future generations value}

Because our post-redistribution inequality is close to that in Denmark, we have used this as the benchmark - i.e., we have assumed that outcomes converge on those experienced in Denmark, controlling for population size and calculating the resulting savings in UK terms.

Over the 40 years to 2050, we estimate that this would create cumulative social value of $£ 3,655$ billion as shown by the pink line in Figure 2.
The final form of value creation is environmental. Put another way, it is the value that would be preserved for future generations in the Great Transition relative to two possible business as usual scenarios. In each case we estimate the environmental impacts of business as usual (scenario A and scenario B) and the Great Transition, with the difference between the two being the environmental value created (or degradation avoided).

In order to avoid climate-change-related costs spiralling out of control, reaching a cumulative total of $£ 2.6$ trillion by 2050, the Great Transition sets out plans for a rapid decarbonisation of the economy that keeps global atmospheric carbon dioxide concentrations to $450 \mathrm{ppm}$. While this figure is criticised in many political circles for being unrealistically ambitious, many scientists and progressive governments no longer consider this adequate to prevent dangerous climate change. 450ppm is used here because it derives from an available model and still reveals the characteristics of rapid (if not deep enough) decarbonisation. In this scenario we assume maximum possible efficiency in terms of energy use across all sectors of the economy, and lowest possible carbon intensity of energy as currently understood.

\section{Total value}

Moreover, we assume that the UK progressively reduces its carbon footprint so that it uses only its fair share of total global carbon emissions under the given, interim target, making sure that other countries, particularly developing countries, have space to develop and make their own transition to a sustainable future. We assume a global 'deal' based on 'contraction and convergence' to limit, reduce and maintain total global emissions within defined limits (the contraction); we also assume that the UK's total share of emissions progressively comes into line with its fair global share (the convergence), with significant transfer payments to developing countries during the process to facilitate their sustainable development.
So how does the total value created across the individual, social and environmental dimensions compare with the loss in GDP over this period? Under both the Climate Change Act and WEO scenarios, the total value created exceeds cumulative reduction in GDP of $£ 7,360$ billion from 2010 to 2050. In other words, figure 3 shows that while we do we have to give up something in the course of the Great Transition, we also potentially stand to gain in the form of greater social and environmental value.

\section{It is possible and necessary}

The Great Transition project is but a first step in envisaging how an economy and society that delivers positive social outcomes and exists within environmental limits can take shape. It is not intended to be prescriptive, but to show that fundamental change is possible. Sizeable challenges remain, not least establishing a macro-economic model that is not dependent on growth. However, change is necessary if we want a sustainable and just future.

\section{References}

Bradshaw, J. et. al.: A minimum income standard for Britain: what people think. York 2008.

Polanyi, K.: The great transformation: the political and economic origins of our times. Boston 1944

Spratt, S. / Simms, A. / Neitzert, E. / Josh R.-C.: The Great Transition. London 2009. Download at: http://www.neweconomics.org/ greattransition

Wilkinson, R.G. / Pickett K.E.: The spirit level: why more equal societies almost always do better. London 2009.

I AUTHORS + CONTACT

Dr. Eva Neitzert is the Head of the Business, Finance and Economics Programme and Dr. Stephen Spratt is Chief Economist at the new economics foundation (nef)

New economics foundation, Eva Neitzert, Tel.: ++20 7820 6375,

E-Mail: eva.neitzert@neweconomics.org Internet: http://www.neweconomics.org 
(c) 20I0 Authors; licensee IÖW and oekom verlag. This is an article distributed under the terms of the Creative Commons Attribution Non-Commercial No Derivates License (http://creativecommons.org/licenses/by-nc-nd/3.o/), which permits unrestricted use, distribution, and reproduction in any medium, provided the original work is properly cited. 